ARTIGO ORIGINAL

\title{
Incorporação de Lactobacillus casei microencapsulado em queijo tipo coalho
}

\author{
Incorporation of encapsulated Lactobacillus casei into type curd cheese \\ Janilton Rodrigues Lima1, Gabriel Olivo Locatelli², Leandro Finkler³, \\ Christine Lamenha Luna-Finkler ${ }^{4}$
}

\section{RESUMO}

Introdução: O queijo tipo coalho é um alimento típico da região nordeste do Brasil, e apresenta características físicoquímicas que permitem a veiculação de micro-organismos probióticos, mas poucos trabalhos tem explorado essa possibilidade.

Objetivo: Avaliar a capacidade de adesividade celular de Lactobacillus casei pelas características de hidrofobicidade e investigar a incorporação deste micro-organismo, na forma livre e encapsulada em alginato de cálcio, em queijo tipo coalho.

Materiais e Métodos: Inicialmente verificaram-se as características de adesividade celular de Lactobacillus casei, por meio de testes de polaridade com xilol (caráter apolar), clorofórmio (caráter ácido) e acetato de etila (caráter básico). Para crescimento celular do micro-organismo, foi elaborado um meio de cultura a base de soro de leite, sendo posteriormente microencapsulado em alginato de cálcio e seco a 35ㄷ․ As microcápsulas secas, assim como as células livres, foram incorporadas durante a elaboração do queijo tipo coalho.

Resultados: Foi possível atingir uma alta concentração celular no meio à base de soro de leite $\left(10^{8} \mathrm{UFC} / \mathrm{mL}\right)$, diminuindo uma unidade logarítmica durante a microencapsulação e secagem. Os queijos apresentaram contagem de

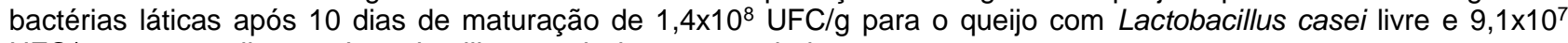
UFC/g para o queijo com Lactobacillus casei microencapsulado.

Conclusão: Desta forma, os queijos obtidos com a introdução de ambas as formas de Lactobacillus casei apresentaram concentrações de células viáveis consideradas adequadas para alimentos probióticos, podendo concluir que o queijo tipo coalho é um produto com características interessantes para a veiculação de micro-organismos probióticos.

Palavras-chave: alginato; microencapsulação; probiótico; queijo coalho; soro de leite.

\begin{abstract}
Introduction: The cheese type curd is a typical food of the northeastern region of Brazil, and its physical-chemical characteristics allows the incorporation of probiotic microorganisms, although few studies have explored this possibility.

Objective: This work aims to evaluate the cell adhesiveness of Lactobacillus casei by its hydrophobicity characteristic and to investigate the incorporation of this micro-organism in both free form and encapsulated in calcium alginate in the curd cheese type.

Materials and Methods: Initially we investigated the characteristics of cell adhesion of Lactobacillus casei, by testing polarity using xylol (nonpolar), chloroform (acid) and ethyl acetate (basic). For cell growth of the micro-organism it was prepared a culture medium based on whey, which was microencapsulated in calcium alginate and dry to $35^{\circ} \mathrm{C}$. The dried microcapsules, as well the free Lactobacillus casei cells, were incorporated during the preparation of the cheese.

Results: According to the results, it was possible to achieve a high cell concentration in the culture medium based on whey (10 $\mathrm{UFC} / \mathrm{mL})$, decreasing one logarithmic cycle during the drying and microencapsulation. The cheeses had counts of lactic acid bacteria after 10 days of maturation of $1,4 \times 10^{8} \mathrm{UFC/g}$ (cheese with free Lactobacillus casei) and $9,1 \times 10^{7} \mathrm{UFC} / g$ (cheese with microencapsulate Lactobacillus casei).

Conclusions: Thus, cheeses made with the introduction of both forms of Lactobacillus casei showed viable cell concentrations considered adequate for food probiotics. It can be concluded that the cheese type curd is a product with characteristics of interest for the incorporation of probiotic microorganisms.
\end{abstract}

Keywords: alginate; microencapsulation; probiotic; cheese type curd; whey.

${ }^{1}$ Nutricionista graduado pela Universidade Federal de Pernambuco (UFPE).

'Bacharel em Biotecnologia Industrial. Mestre em Biotecnologia Industrial e Doutorando em Biotecnologia (UFPE).

${ }^{3}$ Engenheiro de Alimentos. Doutor em Engenharia Química pela Universidade Federal do Rio de Janeiro (UFRJ). Docente do Centro Acadêmico de Vitória (UFPE).

${ }^{4}$ Engenheira Química. Doutora em Engenharia Química pela UFRJ. Docente do Centro Acadêmico de Vitória (UFPE). 


\section{INTRODUÇÃO}

O papel da alimentação equilibrada na manutenção da saúde e bem estar, vêm despertando cada vez mais o interesse do público consumidor. Em contrapartida, a comunidade científica busca comprovar a atuação desses alimentos na promoção de saúde e prevenção de doenças. Recentemente inúmeras pesquisas nesta área têm dado subsídios para o desenvolvimento de novos produtos alimentícios com a alegação de propriedades funcionais. Dentre os alimentos que se enquadram nesta categoria, os probióticos se destacam pelas suas vantagens e aplicações, estando principalmente disponíveis em produtos lácteos.

Segundo a $\mathrm{FAO} / \mathrm{WHO}^{1}$ os probióticos são definidos como micro-organismos vivos que quando administrados em quantidades adequadas afetam positivamente a saúde do hospedeiro. Devem ser inócuos, não patogênicos, manter-se viáveis após processamento tecnológico, ter vida de prateleira longa, apresentar resistência ao $\mathrm{pH}$ baixo do suco gástrico e à ação das secreções pancreáticas e biliares, além de terem a capacidade de colonizar 0 cólon ${ }^{1,2}$. A adesão dos probióticos a mucosa intestinal depende da hidrofobicidade e da composição da parede celular, da existência de receptores e ligantes como as adesinas e de elementos de fixação que impedem sua eliminação pelo peristaltismo intestinal, impedindo sua excreção pelas fezes ${ }^{3}$. Devido a essas características os probióticos colonizam a mucosa intestinal, diminuindo o $\mathrm{pH}$ e dificultando a proliferação de bactérias patogênicas, alguns trabalhos mostram que esse efeito de acidificação favorece a absorção de minerais como o cálcio e o ferro, fortalecendo a composição óssea ${ }^{2,4}$.

Apesar da grande diversidade de micro-organismos probióticos, Lactobacillus e Bifidobacterium são os mais comumente adotados pela indústria laticinista ${ }^{5-7}$. Em queijos destaca-se a adição de bactérias do gênero Bifidobacterium, havendo poucos estudos científicos que relatam a incorporação de Lactobacillus a este tipo de alimento. O grupo Lactobacillus casei tem grande valor comercial devido à vasta diversidade de alimentos que podem ser introduzidos, conferindo aroma, sabor, textura e ainda auxiliando na bioconservação dos alimentos pelo processo de acidificação ${ }^{4}$.
Os queijos frescos possuem $\mathrm{pH}$, conteúdo lipídico e atividade de água adequados para adição de probióticos, além de matriz sólida, a qual pode proteger os probióticos com maior eficiência durante a elaboração, estocagem e também, durante o trânsito no organismo humano ${ }^{8,9}$. Dentre os queijos frescos o queijo coalho é um dos mais tradicionais e difundidos na região Nordeste do Brasil, fabricado principalmente nos estados de Pernambuco, Ceará, Rio Grande do Norte e Paraíba ${ }^{10}$. Legalmente, é obtido por coagulação do leite com coalho ou outras enzimas coagulantes, complementada ou não por ação de bactérias láticas selecionadas. É classificado como queijo de massa semi-cozida ou cozida, de média a alta umidade e com teor de gordura nos sólidos totais entre 35 e $60 \%{ }^{11}$.

O queijo coalho geralmente é produzido artesanalmente, em unidades de produção caseira ou em pequenas propriedades rurais ${ }^{12,13}$. Em geral é elaborado a partir de leite cru, sendo muitas vezes o leite obtido sob condições de ordenha deficientes em higiene, o que leva à contaminação do produto final. Vários estudos sobre a qualidade microbiológica de queijo coalho relataram a ocorrência de microorganismos patogênicos e deterioradores em números que excedem aos limites estabelecidos pela legislação. Dentre as bactérias patogênicas observadas destacamse Salmonella spp., Escherichia coli e Staphylococcus aureus ${ }^{13-17}$. Desta forma, a veiculação de microorganismos probióticos a este tipo de alimento, pode ser uma alternativa para a redução desses contaminantes.

Fatores como acidificação do produto final, ácidos produzidos durante o armazenamento, nível de oxigênio no produto, permeação do oxigênio através da embalagem e compostos antimicrobianos presentes no leite, podem reduzir a viabilidade dos probióticos durante o período de armazenamento ${ }^{7}$, outro fator é a sensibilidade às condições gástricas do estomago que reduz a viabilidade desses micro-organismos antes de atingirem o cólon intestinal. Para minimizar esses problemas, algumas técnicas podem ser empregadas, como a utilização de métodos de microencapsulação ${ }^{18,19}$.

A microencapsulação emprega polímeros naturais, que por diferentes técnicas de aprisionamento, 
envolvem os micro-organismos permitindo o aumento da resistência das células à ação de fatores ambientais. Há diversos tipos de polímeros empregados para microencapsulação, entretanto na indústria de alimentos um dos mais utilizados é o biopolímero alginato de sódio, que em presença de cálcio e outros íons divalentes pode trocar o íon sódio de sua estrutura por um íon divalente, gelificando o meio em que se encontra, as microcapsulas formadas resistem as condições ácidas do estomago, sendo dissolvidas ao chegarem ao colón intestinal ${ }^{18-20}$.

Desta forma, o presente trabalho teve o objetivo de avaliar a capacidade de adesividade celular de Lactobacillus casei, pelas características de hidrofobicidade e, investigar a incorporação deste microorganismo, na forma livre e encapsulada em alginato de cálcio, em queijo tipo coalho.

\section{MATERIAIS E MÉTODOS}

\section{Micro-organismo}

A cepa de Lactobacillus casei foi obtida da coleção de culturas do Departamento de Antibióticos da UFPE e mantida em tubos contendo meio MRS Ágar (adicionado de $2,0 \% \mathrm{p} / \mathrm{v}$ de glicose), sendo armazenada em geladeira $\left(4^{\circ} \mathrm{C}\right.$ a $\left.8^{\circ} \mathrm{C}\right)$ e submetida a repiques periódicos.

\section{Ensaios de adesividade de Lactobacillus casei}

Os ensaios de adesividade foram realizados em triplicata, de acordo com a metodologia descrita por Barbosa $^{20}$. A partir de uma cultura mantida em MRS Agar, foi preparada uma suspensão de Lactobacillus casei em $35 \mathrm{~mL}$ de tampão fosfato $(50 \mathrm{mM}$, pH 7,0$) \mathrm{com}$ turbidez equivalente a 2,0 na escala Mcfarland. Em seguida, a suspensão foi centrifugada a 4000rpm por 15 minutos, o sobrenadante foi descartado e as células lavadas por duas vezes com a adição de $35 \mathrm{~mL}$ do tampão fosfato. Por fim, o centrifugado foi ressuspenso em $50 \mathrm{~mL}$ de $\mathrm{KNO}_{3}$.

Em diferentes tubos de ensaio foram adicionados $1 \mathrm{~mL}$ dos solventes xilol (caráter apolar), clorofórmio (caráter ácido) e acetato de etila (caráter básico) e $4 \mathrm{~mL}$ de suspensão celular. Após a mistura célula-solvente, as amostras ficaram em repouso por 5 minutos, seguidas de agitação em vórtex por 2 minutos. Após repouso de 60 minutos foram realizadas leituras de absorbância da fase aquosa a $600 \mathrm{~nm}$ em espectrofotômetro. As análises foram realizadas em triplicata.

O percentual de adesão foi determinado de acordo com a Equação 1:

$\%$ adesão da parede celular $=\frac{(D O A-D O B) \times 100}{D O A}$

Onde, DOA é a densidade óptica da amostra (branco - $5 \mathrm{~mL}$ de solução de $\mathrm{KNO}_{3}$, amostra $-5 \mathrm{~mL}$ de solução de $\mathrm{KNO}_{3}$ + células) e DOB é a densidade óptica do branco (branco $-4 \mathrm{~mL}$ de solução de $\mathrm{KNO}_{3}+1 \mathrm{~mL}$ dos solventes, amostra $-4 \mathrm{~mL}$ de suspensão celular em solução de $\mathrm{KNO}_{3}+1 \mathrm{~mL}$ dos solventes).

\section{Condições de cultivo}

Foi preparado um pré-inóculo em solução salina estéril, com turbidez equivalente a 0,5 na escala McFarland, a partir da cultura fresca crescida em MRS Agar. Um volume de $5 \mathrm{~mL}$ do pré-inóculo foi transferido para um frasco Erlenmeyer (250mL de capacidade), contendo $45 \mathrm{~mL}$ de meio caldo MRS adicionado de $2 \%$ de glicose $(p / v)$, representando uma concentração de pré-inóculo de $10 \%(\mathrm{v} / \mathrm{v})$. As células foram incubadas sob condição estacionária a $37^{\circ} \mathrm{C}$ por 12 horas, para a obtenção do inóculo.

O crescimento celular foi realizado em meio de cultura formulado à base de soro de leite, que apresentou a seguinte composição em $\mathrm{g} / \mathrm{L}: \mathrm{MnSO}_{4} \cdot \mathrm{H}_{2} \mathrm{O} \quad(0,05)$; $\mathrm{MgSO}_{4} .7 \mathrm{H}_{2} \mathrm{O}(0,10)$; citrato de sódio $(2,00)$; acetato de sódio (5,00); $\mathrm{K}_{2} \mathrm{HPO}_{4}(2,00)$; glicose $(40,00)$; tween 80 $(1,00)$; extrato de levedura $(25,00)$; soro de leite (qsp $1,0 \mathrm{~L}$ de meio). O soro foi gentilmente cedido pela empresa Natural da Vaca®, localizada em Gravatá - PE.

Os cultivos foram realizados em frascos Erlenmeyers (500mL de capacidade), contendo $200 \mathrm{~mL}$ de meio. Foi empregada uma concentração de inóculo de 5\% (v/v) e os frascos foram incubados sob condição estacionária à $37^{\circ} \mathrm{C}$ por 48 horas.

Visando à obtenção de um concentrado de células para os ensaios de encapsulação, o caldo fermentado foi centrifugado, sob refrigeração, a $10^{\circ} \mathrm{C}$ (Hermle®), modelo Z36HK) a 4000rpm por 15 minutos. Amostras do 
final do cultivo e da suspensão celular concentrada foram retiradas para determinação da concentração de células viáveis, expressa em UFC/mL.

\section{Microencapsulação de Lactobacillus casei}

As microcápsulas foram preparadas a partir de uma solução de alginato de sódio (Danisco®) a uma concentração de $1 \%(p / v)$ em água destilada estéril, solubilizado em banho-maria a $50^{\circ} \mathrm{C}$ sob agitação constante.

A suspensão celular concentrada foi misturada à solução de alginato na proporção de 1:4 (v/v), formando uma suspensão (célula/alginato) que foi gotejada com uma seringa de $20 \mathrm{~mL}$ em um volume de $100 \mathrm{~mL}$ de uma solução de $\mathrm{CaCl}_{2}(0,1 \mathrm{M})$ sob leve agitação. As microcápsulas formadas foram mantidas sob refrigeração a $8^{\circ} \mathrm{C}$ por 2 horas, sendo posteriormente lavadas duas vezes com solução salina estéril 0,85\% $(\mathrm{p} / \mathrm{v})$. Após pesagem das partículas úmidas, estas foram submetidas à secagem em estufa com circulação de ar a 35 $\mathrm{C}$ até peso constante.

O armazenamento das microcápsulas após a secagem foi realizado em um frasco hermeticamente fechado mantido em geladeira $\left(2^{\circ} \mathrm{C}\right.$ à $\left.8^{\circ} \mathrm{C}\right)$. Amostras da suspensão células/alginato e das partículas secas foram retiradas para determinação da concentração de células viáveis.

Preparo do queijo de coalho com Lactobacillus casei livres e microencapsulados

Para o preparo do queijo de coalho foi utilizado leite pasteurizado e padronizado, adquirido em supermercado na cidade de Vitória de Santo Antão PE. As embalagens foram higienizadas antes de serem abertas e manipuladas de acordo com as normas de boas práticas de fabricação. Com o objetivo de avaliar suas características microbiológicas, o produto foi submetido à contagem de bactérias totais em meio PCA, contagem de células em meio MRS Agar (seletivo para bactérias láticas) e plaqueamento em EMB, recomendado para o isolamento e diferenciação de bactérias entéricas Gram-negativas.

O processo de fabricação do queijo coalho foi baseado nos trabalhos de Cavalcante et al. ${ }^{16}$ e Laguna e Egito ${ }^{21}$, com algumas modificações para a adição dos micro-organismos. $\mathrm{O}$ leite foi aquecido à $65^{\circ} \mathrm{C}$ e mantido por 30 minutos para pasteurização, em seguida resfriado a $37^{\circ} \mathrm{C}$; adição lenta de $\mathrm{CaCl}_{2}(0,05 \% \mathrm{p} / \mathrm{v}$, previamente diluído em $10 \mathrm{~mL}$ de água destilada); adição lenta do coalho $(0,0625 \mathrm{~g} / \mathrm{L}$, previamente diluído em $10 \mathrm{~mL}$ de água destilada); repouso por 50 minutos; corte da coalhada com o auxílio de liras horizontais e verticais; mexedura da coalhada; realização da dessoragem; salga da massa (concentração de sal de $0,4 \% \mathrm{p} / \mathrm{v})$; enformagem; prensagem manual; desenformagem; maturação e pesagem.

A massa total obtida foi dividida em 2 porções, uma para a adição do Lactobacillus casei livre e a outra para a adição do Lactobacillus casei microencapsulado. A adição dos micro-organismos probióticos foi realizada na etapa de enformagem, adicionando-se 0,01\% (p/p) de microcápsulas ou $0,01 \%(\mathrm{v} / \mathrm{p})$ de suspensão celular concentrada (diluída em $1,0 \mathrm{~mL}$ de soro de leite) para $200 \mathrm{~g}$ de massa. A prensagem foi realizada por um período de 14 horas a temperatura ambiente; em seguida, os queijos foram retirados das formas, pesados novamente, embalados em um tecido estéril e colocados em refrigerador a $10^{\circ} \mathrm{C}$ para maturação por 7 dias. Após este período, foram retiradas amostras para contagem das células probióticas e caracterização físico-química.

\section{Métodos analíticos}

Contagem de Células Viáveis: todas as amostras foram submetidas às diluições decimais seriadas em tubos de ensaio contendo solução salina estéril $(0,85 \%$ p/v). Em seguida, um volume de $100 \mu \mathrm{L}$ de diferentes diluições foi inoculado em placas de Petri contendo meio MRS Ágar (suplementado com $2 \%$ de glicose $\mathrm{p} / \mathrm{v}$ ) pela técnica de "pour plate". As placas foram incubadas em estufa por 72 horas a $37^{\circ} \mathrm{C}$ e após a contagem, as colônias foram expressas em UFC/mL ou UFC/g. Para a contagem nos queijos, amostras de $25 \mathrm{~g}$ foram diluídas em Erlenmeyers, de $500 \mathrm{~mL}$ de capacidade, contendo $225 \mathrm{~mL}$ de água peptonada estéril $(0,1 \% \mathrm{p} / \mathrm{v})^{22}$, enquanto que para a contagem nas microcápsulas, a primeira diluição foi realizada em solução de citrato de sódio $(2 \% \mathrm{p} / \mathrm{v})$ para a completa dissolução das 


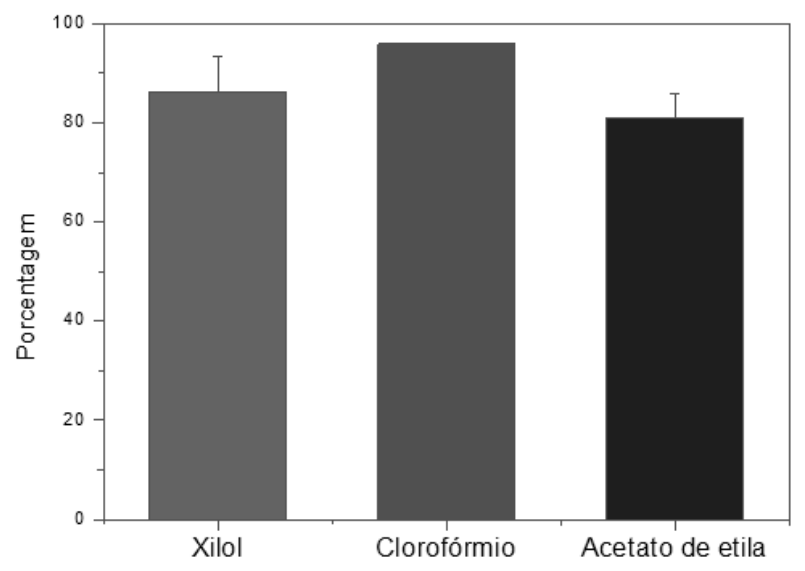

FIGURA 1 - Porcentagem de hidrofobicidade e características ácido-básicas da parede celular de Lactobacillus casei.

microcápsulas. Em ambos os casos, foi realizado o mesmo procedimento de diluições seriadas e incubação, descrito acima.

Caracterização Físico-química dos Queijos: foi realizada de acordo com as metodologias analíticas oficiais para as análises de cinzas, gordura, umidade, nitrogênio total e $\mathrm{pH}^{23}$.

\section{RESULTADOS}

Os resultados de hidrofobicidade e das características ácido básicas podem ser observados na figura 1. 0 solvente xilol possui caráter apolar, e quanto maior a solubilidade das células nesse solvente, maior o grau de hidrofobicidade. Desta forma, as células de Lactobacillus casei apresentaram um elevado grau de hidrofobicidade, atingindo $86,3 \pm 7,2 \%$. Já o solvente clorofórmio apresenta um caráter ácido, enquanto o acetato de etila apresenta um caráter básico. As células de Lactobacillus casei foram mais solúveis em clorofórmio $(95,9 \pm 3,0 \%)$ do que em acetato de etila $(81,0 \pm 5,0 \%)$, indicando uma superfície celular mais ácida.

O preparo do inóculo em caldo MRS (suplementado com $2 \%$ de glicose $\mathrm{p} / \mathrm{v}$ ) foi acompanhado durante 12 horas de cultivo, apresentando uma fase exponencial de crescimento entre 9 e 11 horas, com velocidade máxima de crescimento $\left(\mu_{\operatorname{Max}}\right)$ de $0,40 \mathrm{~h}^{-1}$. Desta forma, foi definido em 10 horas o tempo favorável para a transferência do inóculo para o meio de cultivo.

$\mathrm{O}$ cultivo no meio à base de soro de leite cresceu
TABELA 1 - Concentração de células viáveis de Lactobacillus casei durante 0 processo de microencapsulação.

\begin{tabular}{lc}
\hline \multicolumn{1}{c}{ Amostra } & $\begin{array}{c}\text { Concentração de células } \\
\text { viáveis }\end{array}$ \\
\hline Caldo fermentado & $6,90 \times 10^{8} \mathrm{UFC} / \mathrm{mL}$ \\
Suspensão celular concentrada & $1,65 \times 10^{10} \mathrm{UFC} / \mathrm{mL}$ \\
Suspensão células/alginato & $4,15 \times 10^{9} \mathrm{UFC} / \mathrm{mL}$ \\
Microcápsulas secas & $7,40 \times 10^{7} \mathrm{UFC} / \mathrm{g}$ \\
\hline
\end{tabular}

exponencialmente entre 5 e 48 horas, sendo obtida uma concentração final de células viáveis $6,9 \times 10^{8} \mathrm{UFC} / \mathrm{mL}$, adequada para o uso do caldo fermentado como inoculante em alimentos com características probióticas. O caldo fermentado foi concentrado por centrifugação e a suspensão celular concentrada foi utilizada na inoculação do queijo de coalho e no preparo das microcápsulas contendo Lactobacillus casei.

Nos ensaios de microencapsulação foi possível obter, a partir de $20 \mathrm{~mL}$ de suspensão célula/alginato, uma massa de $7,3 \mathrm{~g}$ de microcápsulas úmidas, um rendimento de 36,5\%. Essas partículas foram submetidas à secagem a $35^{\circ} \mathrm{C}$ em estufa de circulação de ar, até apresentarem peso constante, que foi atingido com 3 horas de secagem. O aspecto das microcápsulas úmidas e secas pode ser observado na figura 2 .

Os resultados de concentração de células viáveis nas amostras do caldo fermentado, suspensão celular concentrada, suspensão de células/alginato e nas microcápsulas secas estão apresentados na tabela 1 .

O leite empregado na fabricação dos queijos apresentou contagem de bactérias totais e lácticas de $2,2 \times 10^{3} \mathrm{UFC} / \mathrm{mL}$ e $4,0 \times 10^{2} \mathrm{UFC} / \mathrm{mL}$ respectivamente, não sendo observado crescimento de micro-organismos no meio EMB. Os queijos apresentaram um rendimento final da massa úmida de aproximadamente $10 \%$ da massa inicial de leite, o que está de acordo com o rendimento esperado para esse tipo de queijo.

TABELA 2 - Composição centesimal dos queijos realizada após 10 dias de preparo.

\begin{tabular}{lcc}
\hline $\begin{array}{c}\text { Componente } \\
(\%)\end{array}$ & $\begin{array}{c}\text { Queijo } \\
\text { suplementado } \\
\text { com células livres }\end{array}$ & $\begin{array}{c}\text { Queijo suplementado } \\
\text { com células } \\
\text { encapsuladas }\end{array}$ \\
\hline Proteínas & 25,3 & 26,0 \\
Carboidratos & 5,0 & 12,3 \\
Lipídios & 38,0 & 38,0 \\
Umidade & 28,9 & 20,7 \\
Cinzas & 2,8 & 3,0 \\
\hline
\end{tabular}



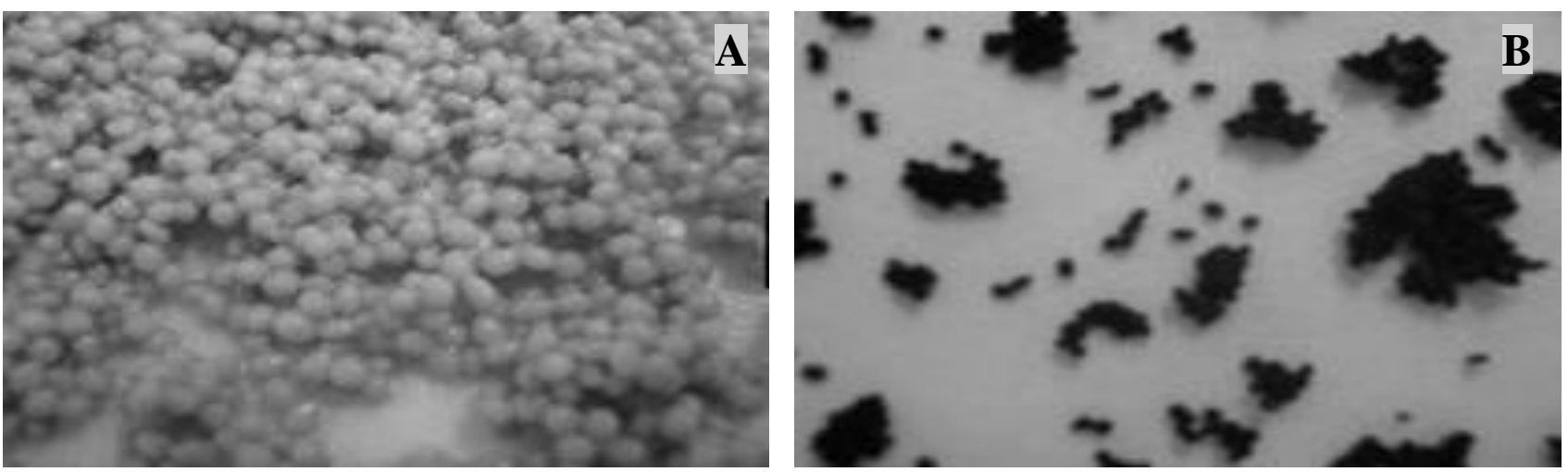

FIGURA 2 - Microcápsulas de Lactobacillus casei úmidas (A) e secas (B).

A contagem de bactérias lácticas após 10 dias de maturação foi de $1,4 \times 10^{8} \mathrm{UFC} / \mathrm{g}$ para o queijo com Lactobacillus casei livre e $9,1 \times 10^{7} \mathrm{UFC} / \mathrm{g}$ para o queijo com Lactobacillus casei microencapsulado. Os resultados relativos à composição centesimal dos queijos estão apresentados na tabela 2.

\section{DISCUSSÃO}

Segundo Pelletier24 estudos físico-químicos de superfícies celulares microbianas têm demonstrado relações entre cargas superficiais, hidrofobicidade e a composição elementar da superfície celular. Como compostos mediadores de adesão destacam-se as adesinas, que possuem caráter hidrofóbico, mas a adesão pode ainda ser mediada por outros fatores associados à superfície bacteriana, como os ácidos lipoteicóicos e exopolissacarídeos presentes nas células dos micro-organismos ${ }^{25,26}$. Nas condições investigadas, a cepa de Lactobacillus casei utilizado apresentou características de hidrofobicidade e de superfície celular com caráter ácido que indicam um bom potencial de adesão ao epitélio intestinal, confirmando seu potencial probiótico.

Silveira $^{27}$ realizou fermentações de Lactobacillus casei em um meio sintético ( $\mathrm{pH} 6,5$ e $\left.37^{\circ} \mathrm{C}\right)$, com a finalidade de obtenção de ácido lático e observaram uma maior taxa específica de crescimento celular $\left(0,61 \mathrm{~h}^{-1}\right)$. No entanto, este estudo foi realizado com um meio de cultura contendo $50 \mathrm{~g} / \mathrm{L}$ de açúcares redutores, superior à quantidade utilizada no presente trabalho, que foi de $20 \mathrm{~g} / \mathrm{L}$ de glicose.

Segundo a ANVISA, a quantidade mínima de microorganismos probióticos viáveis deve estar situada na faixa de $10^{8}$ a $10^{9}$ UFC na recomendação diária do produto pronto para o consumo, conforme indicação do fabricante ${ }^{28}$. Como podemos observar, o caldo fermentado já apresenta uma concentração celular satisfatória para ser considerado um produto probiótico. Com a centrifugação essa concentração aumenta em 2 ciclos logarítmicos atingindo $1,65 \times 10^{10} \mathrm{UFC} / \mathrm{mL}$.

As microcápsulas secas apresentam uma diminuição no número de células viáveis devido ao processo de secagem. Esta etapa é necessária para a obtenção de um produto estável e de fácil manipulação, podendo a amostra ser armazenada e transportada com maior facilidade. De acordo com Terra et al. ${ }^{29}$, as microcápsulas úmidas podem ser alvo fácil de contaminação, sendo necessária a rápida secagem logo após o processo de microencapsulação. Nas microcápsulas os micro-organismos encontram-se envolvidos por uma camada de alginato, o que confere uma proteção adicional e permite um aumento da resistência das células à ação dos fluidos biológicos gerados no processo de digestão ${ }^{18,19,29}$.

Como estabelecido pela ANVISA, valores menores que $10^{8}$ e $10^{9}$ UFC podem ser aceitos, desde que comprovada sua eficácia. Há trabalhos que propõem que a dose mínima diária de culturas probióticas considerada terapêutica corresponda ao consumo de $100 \mathrm{~g}$ de produto contendo $10^{6}$ a $10^{7} \mathrm{UFC} / \mathrm{g} 4,28,30,31$. Desta forma, as microcápsulas secas podem ser uma alternativa interessante para a inoculação de microorganismos probióticos em alimentos.

Como indicado pela análise do leite utilizado na fabricação dos queijos, este apresentou uma contagem inicial de bactérias lácticas, de acordo com padrões 
estabelecidos pela legislação ${ }^{32}$. O leite contém naturalmente bactérias lácticas e algumas espécies como Streptococcus thermophilus, podem sobreviver ao processo de pasteurização ${ }^{33}$. Outras espécies de bactérias lácticas podem também contaminar o leite após este processo.

O queijo com Lactobacillus casei microencapsulado apresentou uma contagem de bactérias lácticas abaixo do queijo com Lactobacillus casei livres, onde obtivemos - maior número de células viáveis, fato também verificado por Godward e Kailasapathy ${ }^{34}$. Isso pode ocorrer pelo fato do micro-organismo microencapsulado não ter a mesma mobilidade de colonizar os queijos como os micro-organismos livres. Ainda segundo os autores, a matriz do alimento, que é muito complexa, pode impedir a troca de nutrientes e metabólitos entre as microcápsulas e o ambiente externo ${ }^{34}$. Por outro lado, as células microencapsuladas tem uma maior resistência à ação dos fluidos biológicos, podendo chegar com maior viabilidade ao cólon intestinal ${ }^{20,35}$. Esse aumento da resistência às condições ácidas do estômago foi comprovado por Oliveira ${ }^{35}$, onde nos tratamentos em $\mathrm{pH} 1$ e 3 por 3 horas, as células de L. acidophilus encapsuladas com pectina e caseína não diminuíram sua viabilidade celular, enquanto células livres reduziram em até 3 ciclos logarítmicos sua população microbiana.

A suspensão celular concentrada obtida pela fermentação em meio à base de soro de leite pode ser uma alternativa viável para a inoculação de Lactobacillus casei em queijo coalho produzido pelos pequenos laticínios produtores. O produto obtido pode ser considerado um alimento probiótico, visto que a contagem de células viáveis apresenta-se de acordo com a legislação específica ${ }^{28}$. No entanto, o queijo coalho com Lactobacillus casei microencapsulado por alginato de cálcio, também pode ser uma alternativa tecnológica interessante, pois pode garantir uma maior viabilidade das células ao chegarem ao cólon intestinal.

De acordo com o MAPA pela Instrução Normativa $\mathrm{n}^{\circ}$ 30 de 26 de junho de 2001, que aprova os regulamentos técnicos de identidade e qualidade do queijo de coalho $^{11}$, o queijo de coalho é um queijo de média a alta umidade, sendo considerados queijos de média umidade os que apresentam entre 36,0 e $45,9 \%$ de água e queijos de alta umidade os que apresentam entre 46,0 e $54,9 \%$ de água. O baixo teor de umidade observado nos queijos obtidos neste estudo pode ser explicado pelo fato de que a análise físico-química foi realizada após 10 dias de sua fabricação, havendo uma perda de umidade neste período. Os demais resultados físico-químicos se encontram de acordo com a legislação ${ }^{11}$ e com os resultados observados por Machado $^{10}$. Essas características fazem do queijo coalho um produto interessante para a veiculação de micro-organismos probióticos.

\section{Agradecimentos}

Os autores agradecem à empresa Natural da Vaca®, por ter cedido o soro de leite. Ao apoio financeiro dos órgãos de fomento, Fundação de Amparo à Ciência e Tecnologia do Estado de Pernambuco (FACEPE), Pró-Reitoria de Pesquisa da Universidade Federal de Pernambuco (PROPESQ), e ao Conselho Nacional de Desenvolvimento Científico e Tecnológico (CNPq).

\section{REFERÊNCIAS}

1. FAOMHO. Food and Agriculture Organization of the United Nations. Health and nutritional properties of probiotics in food including powder milk with live lactic acid bacteria. Córdoba: FAO; 2001. 34p.

2. Lavanda I, Saad SMI, Lobo AR, Colli C. Prebióticos y su efecto em la biod sponibilidad del cálcio. Rev Nutr. 2011; 24(2):333-44

3. Barbosa FH, Silva AM, Martins FS, Nicoli JR. Perfil de hidrofobicidade da superfície celular de Bifidobacterium lactis $\mathrm{Bb} 12$ e Bifidobacterium longum Bb46 em função do meio de cultura. Rev Biol Ciênc Terra. 2005; 5(2):1-11.

4. Buriti FCA, Saad SMI. Bactérias do grupo Lactobacillus casei: caracterização, viabilidade como probióticos em alimentos e sua importância para a saúde humana. Arch Lat Nutr. 2007;57(4):373-80.

5. Hauly MCO, Fuchs RHB, Prudencio-Ferreira SH. Suplementação de iogurte de soja com frutooligossacarídeos: características probióticas e aceitabilidade. Rev Nutr. 2005;18(5):613-22.

6. Alves LL, Mattanna P, Becker LV, Richards NSPS, Andrade DF. Avaliação sensorial de cream cheeses potencialmente simbióticos utilizando a metodologia de superfície de resposta. Alim Nutr. 2008;19(4):409-16.

7. Kailasapathy K, Chin J. Survival and therapeutic potential of probiotic organisms with reference to Lactobacillus acidophilus and Bifidobacterium spp. Immunol Cell Biol. 2000;78:80-8.

8. Kasimoglu A, Goncuoglu M, Akgun S. Probiotic white cheese with Lactobacillus acidophilus. Int Dairy J. 2004; 14:1067-73.

9. Bergamini CV, Hynes ER, Quiberoni A, Zalazar CAI. Probiotic bactéria as adjunct starters: influence of the 
addition methodology on their survival in a semi-hard Argentinean cheese. Food Res. Int. 2004; 38(5):597-604.

10. Machado GM, Costa EGB, Costa Junior LCG, Sobral D, Taveira LB, Souza BM. Aspectos físico-químicos de queijo de coalho fabricado com o uso de ácido lático. Alim Nutr $2011 ; 22(3): 421-8$.

11. Brasil. Ministério da Agricultura, Pecuária e Abastecimento. Inst. Normativa № 30, de 26 de junho de 2001. Regulamentos Técnicos de Identidade e Qualidade de Queijo de Coalho, 2001. Brasília (DF): Ministério da Agricultura, Pecuária e Abastecimento; 2001.

12. Leite CC, Guimarães AG, Ribeiro NS, Silva MD, Assis PN. Pesquisa de Listeria monocytogenes e Escherichia coli em queijo do tipo "Coalho" comercializado em Salvador (BA) Importância para a saúde pública. Rev Analyt. 2002; 2:3841.

13. Meneses RB, Cardoso RCV, Guimarães AG, Góes JAW, Silva AS, Argolo SV. O comércio de queijo de coalho na orla de Salvador, Bahia: trabalho infantil e segurança de alimentos. Rev Nutr. 2011; 25(3):381-92.

14. Feitosa T, Borges MF, Nassu RT, Azevedo ÉHF, Muniz CR. Pesquisa de Salmonella $\mathrm{sp}$., Listeria $\mathrm{sp}$. e microrganismos indicadores higiênico-sanitários em queijos produzidos no estado do Rio Grande do Norte. Ciênc Tecnol Aliment. 2003; 23:162-5.

15. Oliveira OMAB, Bastos MSR, Fontenele MA, Oliveira CW, Silva APV. Adequação da produção de leite para queijo coalho, conforme a Instrução Normativa No 51. Rev Hig. Alim. 2010; 24(182):97-102

16. Cavalcante JFM, Andrade NJ, Furtado MM, Ferreira CLLF, Pinto CLO, Elard E. Processamento do queijo coalho regional empregando leite pasteurizado e cultura lática endógena. Ciênc Tecnol Aliment. 2007; 27(1):205-14

17. Santana RF, Santos DM, Martinez ACC, Lima ÁS. Qualidade microbiológica de queijo-coalho comercializado em Aracaju, SE. Arq Bras Med Vet Zootec. 2008; 60(6):1517-22

18. Souza FN, Gebara C, Ribeiro MCE, Chaves KS, Gigante $\mathrm{ML}$, Grosso CRF. Production and characterization of microparticles containing pectin and whey proteins. Food Res Int. 2012; 49:560-6.

19. Pawar KS, Pawar SP, Patel VA. Microbial polysaccharidases in colon specific drug delivery. Int $J$ Pharm Scienc Rev Res 2011; 6(2):188-96.

20. Favaro-Trindade CS, Pinho SC, Rocha GA. Revisão: microencapsulação de ingredientes alimentícios. Braz $J$ Food Technol. 2008;11(2):103-12.

21. Laguna LE, Egito AS. Processamento do queijo de coalho fabricado com leite de cabra maturado e defumado. Sobra (CE): Embrapa; 2008. Comunicado técnico 90, Prática e processo agropecuário.

22. Silva N, Junqueira VCA, Silveira NFA, Taniwaki $\mathrm{MH}$, Santos RFS, Gomes RAR. Manual de Métodos de Análise Microbiológica de Alimentos. $3^{\underline{a}}$ ed. São Paulo: Varela 2010.

23. Brasil. Ministério da Agricultura. Secretaria Nacional de Defesa Agropecuária. Métodos analíticos oficiais para controle de produtos de origem animal e seus ingredientes: II - métodos físicos e químicos. Brasília (DF): Laboratório Nacional de Referência Animal; 1981.
24. Pelletier C, Bouley C, Cayuela C, Bouttier S, Bourlioux P, Bellon-Fontaine MN. Cell surface characteristics of Lactobacillus casei subsp. casei, Lactobacillus paracasei subsp. paracasei, and Lactobacillus rhamnosus strains. Appl Environ Microbiol. 1997;63(5):1725-31.

25. Vélez MP, De Keersmaecker SCJ, Vanderleyden J. Adherence factors of Lactobacillus in the human gastrointestinal tract. FEMS Microbiol Lett. 2007; 276:140-

26. Meira SMM. Potencial probiótico de bactérias lácticas $e$ atividades biológicas de leite e queijos de ovelha [dissertação]. Porto Alegre (RS): UNIJUI/UERGS; 2011. $107 p$.

27. Silveira MS. Utilização do suco de caju clarificado para a produção de ácido lático pelo Lactobacillus casei B-442 [dissertação]. Fortaleza (CE): UFC; 2009. 97p.

28. Brasil. Ministério da Saúde. Agência Nacional de Vigilância Sanitária. IX - lista de alegações de propriedade funcional aprovadas. Atualizado em julho/2008. Alimentos com Alegações de Propriedades Funcionais e ou de Saúde, Novos Alimentos/Ingredientes, Substâncias Bioativas e Probióticos, 2008. Brasília (DF): Ministério da Saúde; 2008

29. Terra NM, Lopes VS, Coutinho-Filho U, Cardoso VL. Produção de probióticos de células imobilizadas de Lactobacillus por fermentação em soro de leite. In: VIII Congresso Brasileiro de Engenharia Química em Iniciação Científica, Uberlândia, 2009; 1-5.

30. Cichoski AJ, Cunico C, Di Luccio M, Zitkoski JL, Carvalho RT. Efeito da adição de probióticos sobre as características de queijo prato com reduzido teor de gordura fabricado com fibras e lactato de potássio. Ciênc Tecnol Aliment. 2008; 28(1):214-9.

31. Komatsu RT, Buriti FCA, Saad SMI. Inovação, persistência e criatividade superando barreiras no desenvolvimento de alimentos probióticos. Rev Bras Ciênc Farm. 2008; 44(3):329-47.

32. Brasil. Ministério da Agricultura, Pecuária $e$ Abastecimento. Inst. Normativa No51, de 18 de setembro de 2002. Brasília (DF): Diário Oficial da União. 20 de setembro de 2002

33. Bruno LM, Carvalho JDG. Microbiota lática de queijos artesanais. Fortaleza (CE): Embrapa Agroindústria Tropical; 2009. Documentos 124. 29p.

34. Godward G, Kailasapathy K. Viability and survival of free and encapsulated probiotic bacteria in cheddar cheese. Milchwissenschaft. 2003; 58:624-7.

35. Oliveira AC. Viabilidade de Lactobacillus acidophilus e Bifidobacterium lactis, microencapsulados por coacervação, seguida de secagem por spray drying e leito de jorro [dissertação]. Ribeirão Preto (SP): Universidade de São Paulo; 2006

\section{Endereço para correspondência:}

Gabriel Olivo Locatell

Rua do Alto do Reservatório $\mathrm{s} / \mathrm{n}^{\circ}$

Vitória de Santo Antão/PE - CEP 55608-680

Telefone: +55 8197941434

Email: gabriel_locatelli@hotmail.com 